\title{
Hands-on training on inhaled devices to boost pharmacy students' performance during inhaler counselling
}

\author{
Nurdiana Jamil ${ }^{\mathbf{1}}$ iD, Wan Nur Syafiqa Wan Norhaidi ${ }^{1}$, Syahiera Farhana Zakaria ${ }^{2}$ \\ ${ }^{1}$ Faculty of Pharmacy, University of Cyberjaya, Selangor, Malaysia \\ ${ }^{2}$ School of Pharmacy, International Medical University, Kuala Lumpur, Malaysia
}

\author{
Keywords \\ Inhaler technique \\ OSCE \\ Pharmacy curriculum \\ Correspondence \\ Nurdiana Jamil \\ Faculty of Pharmacy \\ University of Cyberjaya \\ Persiaran Bestari \\ 63000 Cyberjaya \\ Selangor \\ Malaysia \\ nurdiana@cyberjaya.edu.my
}

\begin{abstract}
Objective: The effective use of inhalers depends on completeness of information from healthcare providers. As pharmacists acquire foundational skills on inhalers from their undergraduate curriculum, the experience and performance of pharmacy students regarding inhaler counselling should be explored. Methods: Pharmacy students who completed their final year of study answered an online questionnaire on their experience with teaching-learning activities on inhalers. Students also underwent an objective structured clinical exam that included Turbuhaler device counselling. Results: 84 students who completed the online questionnaire strongly agreed that the curriculum increased their awareness of different types of inhalers (65.5\%) and specific techniques for use $(64.3 \%)$. Students reported being able to counsel on metered-dose inhaler $(98.8 \%)$ and dry-powder inhaler (92.8\%) techniques. Students performed well (mean=9.4, SD=2.7) at Turbuhaler counselling from a full score of 14 . Conclusions: The current training on inhaler devices was useful for the pharmacy students. Future training should emphasise supplementary advice on inhaler taste and gargling.
\end{abstract}

\section{Introduction}

Effective use of medication is one of the primary focuses of chronic disease management (Holman \& Lorig, 2004). In chronic respiratory diseases such as asthma and chronic obstructive pulmonary disease (COPD), inhaled devices are the mainstay of drug delivery and therapeutic strategy. Inhaler usage is dependent on completing a sequence of steps correctly for effective drug delivery to the lower respiratory tract for therapeutic effect to occur (Rau, 2005). Correct inhaler device technique has a considerable impact on disease management. Performing critical errors while using inhalers will result in lower effective delivery of drugs to sites of action in the lungs ( Rau \& Faarc, 2006; Basheti et al., 2014; Chrystyn et al., 2017). Incorrect use of inhalers has been associated with an increase in healthcare use and poor disease control (Melani et al., 2011; Levy et al., 2013; Van Boven et al., 2014). It thus becomes essential for patients with chronic respiratory diseases to be educated on correct inhaler device use (Restrepo et al., 2008; Price et al., 2013).
Patients are not solely liable for their ability to use inhalers correctly. Non-patient factors influencing the correct use of inhalers include the transfer of inhaler device education from the healthcare provider to the patients (Volerman, Carpenter \& Press, 2020). A systematic review on inhaler use errors by healthcare professionals found inadequate inhaler techniques among the healthcare providers (Plaza et al., 2018). Inadequate inhaler techniques may prevent health providers from adequate teaching and assessment on the correct use of inhalers among patients with chronic respiratory diseases. In practice, pharmacists serve as the gatekeeper to ensure that the patients receive proper education on medication and medical devices before the patients start taking medication. Therefore, pharmacists have a significant role to educate patients on correct inhaler device techniques (Lavorini et al., 2008). Accurate, practical demonstration on inhaler techniques lower the frequency of inhaler misuse (Chrystyn et al., 2017).

University education has been cited as the source of education on inhaler devices for pharmacists. 
Pharmacists receive their first training on using inhaler devices during undergraduate pharmacy study (Basheti et al., 2014). Due to the importance of educating patients on medication and medical device use, it is vital to ensure that pharmacy education adequately provides teaching and training of correct inhaler device handling in the curriculum. Hence, it is imperative to explore the effectiveness of teaching this inhaler foundational skill to the students.

At the University of Cyberjaya, teaching and learning about inhaler devices and inhaler handling is incorporated during the third year of study under the Primary Care and Medication Management in the fouryear Bachelor of Pharmacy (BPharm) programme. Multiple teaching strategies were utilised, including an introductory lecture on chronic respiratory diseases and inhaler devices, followed by a workshop where students participate in hands-on activities in which they use various types of inhalers such as pressurized metereddose inhalers (pMDI), Accuhaler, and Turbuhaler, Handihaler and Respimat. Students also attained additional knowledge and experience with handling inhaler devices during their didactic and experiential learning throughout their third and fourth years of study. Students' retention of inhaler skills was repeatedly measured during an objective structured clinical examination (OSCE) at the end of the course and approximately eight months later during a final progress testing in their final semester of the four-year programme. OSCE has become a common method of assessing pharmacy students' knowledge and skills worldwide (Shirwaikar, 2015) and allows a reliable assessment of discrete tasks and psychomotor skills (Croft et al., 2019).

The abovementioned teaching and learning strategies have been implemented for several years in the curriculum. Despite this, students' perception and experience on inhaler devices teaching and learning have never been explored. In order to ensure that pharmacy graduates are practice-ready and skilled in delivering care to respiratory patients, a study on the students' perception and experience on teaching and learning methods on inhaler devices in the curriculum is important. The study aimed to determine students' perception of inhaler skills gained and to correlate findings with students' performance during an OSCE station on inhaler device (Turbuhaler) counselling.

\section{Methods}

This cross-sectional study was conducted on a cohort of University of Cyberjaya graduates who recently completed their final semester of the four-year BPharm programme as well as the faculty final progress testing pharmacy termed "Pharmacy Professional
Examination". All students of the 2015/2019 cohort who had completed the BPharm curriculum regardless of whether they passed or failed, and who had undertaken the Pharmacy Professional Examination at the end of semester 8 in the year 2019 were approached for inclusion in the study. The study was carried out from September 2019 to October 2019. Students were informed that their participation was voluntary and participation or non-participation in this study would not affect their existing marks or their ability to graduate. This study was approved by CUCMS Research Ethics Review Committee (CRECR); UoC/CRERC/AL-ER (35/2019).

A questionnaire was developed by two faculty members based on previous literature to suit the objectives of this study. The first faculty member had experience in questionnaire development and validation, whereas the other faculty member had experience in respiratory therapeutics and inhaler handling. The questionnaire contained four domains. The first domain consisted of students' baseline use and experience with inhaler devices. The second domain measured students' perception of inhaler device teaching-learning activities in the BPharm curriculum. It consisted of 11 statements requiring a response from a four point-Likert scale, with the score one denoting 'Strongly Disagree' and the score four denoting 'Strongly Agree'. The third domain measured students' perception of inhaler skills that they had gained during the undergraduate curriculum. It consisted of ten statements requiring a response from a four point-Likert scale with the score one denoting 'Not well at all' and the score four denoting 'Very well'. The final domain allowed respondents to rate teaching methods that they perceived useful for gaining knowledge and skills pertaining to inhaler devices as either 'Most helpful', 'Helpful' and 'Least helpful'. All domains were developed based on previous studies and manuals on end-of-session and student satisfaction questionnaires ( Taylor-Powell \& Renner, 2000; Slain et al., 2004; Jeffries \& Rizzolo, 2006; Vyas et al., 2010). After initial development, the questionnaire was piloted on eight final year students for evaluation of face and content validity. Cronbach's alpha reliability coefficient for the perception domains were 0.837 and 0.915, respectively. Necessary revisions were made accordingly.

Prior to data collection, the list of pharmacy students from intake 2015/2019 was obtained for the distribution of the online questionnaire. The link to the online questionnaire was distributed primarily through a text messaging app. A large majority of the students were reachable when contacted through this medium. The online survey data were periodically screened. The participant was contacted again whenever there was a need to clarify the data submitted. The students' OSCE scores for Turbuhaler counselling during the Pharmacy 
Professional Examination were obtained from the Faculty of Pharmacy.

The assessment of Turbuhaler counselling competency during the Pharmacy Professional Examination was based on a standardised rubric modified from Basheti and authors in 2014. Modifications were done by specifying the word Turbuhaler instead of the generic inhaler. Modifications to the rubric also incorporated the additional puff required by the simulated prescription, the extra step of gargling after the usage of inhaled corticosteroid and auxiliary instructions for storage. These modifications had been deemed necessary to gauge the practice-readiness of students in Turbuhaler counselling by the faculty examination vetting committee.

Statistical Package for Social Sciences (SPSS) for Windows version 25.0 was used for statistical analysis. Data was entered into coded variables and analysed using descriptive statistics. Descriptive data were expressed both as frequencies ( $n$ ) and percentage (\%) for experience, students' perceptions and OSCE performance. Where appropriate, data were grouped to determine perception level. Students were given one mark for each correct step on Turbuhaler counselling during OSCE, and no marks were allocated for wrong or missed steps. The calculated score was then correlated with students' perception towards the teaching method given during learning inhaler devices in UoC. Spearman's rank correlation was used to analyse the correlation between OSCE marks and students' perceptions. The Spearman's rank correlation was deemed appropriate due to the ordinal nature of the Likert scale measuring the perception variable. The statistical significance of inferential analysis was set at $p<0.05$.

\section{Results}

One hundred one students from the BPharm session $2015 / 2019$ were eligible to participate in this study. After a pilot study was carried out on eight students, 93 remaining students were eligible to participate in the study. A link to the online questionnaire was then distributed. Eighty-four students completed the online questionnaire, which equated to a response rate of 90.3\%. Students' experiences with inhaler devices within the undergraduate BPharm curriculum are summarised in Table I.

Table I: Students' experience with inhaler devices in the pharmacy curriculum $(\mathrm{N}=\mathbf{8 4})$

\begin{tabular}{ll}
\hline Item & $\mathbf{n ~ ( \% )}$ \\
\hline Hours spent for inhaler device training & $38(45.2 \%)$ \\
\hline$\bullet$ Less than 2 hours & $40(47.6 \%)$ \\
\hline $\begin{array}{l}\text { - }-5 \text { hours } \\
\text { More than } 5 \text { hours }\end{array}$ & $6(7.1 \%)$ \\
\hline Involvement in additional training in inhaler devices & $24(28.6 \%)$ \\
\hline Self-practiced metered-dose inhaler technique in the current semester & $81(96.4 \%)$ \\
\hline Self-practiced dry-powder inhaler technique in the current semester & $74(88.1 \%)$ \\
\hline Ever-experience of teaching inhaler device technique & $49(58.3 \%)$ \\
\hline Self-usage of inhaler devices in daily life & $3(3.6 \%)$ \\
\hline
\end{tabular}

The majority of students strongly agreed that the inhaler devices component in the curriculum is useful for future practice $(83.3 \%)$, increased their awareness of the availability of different inhaler devices and techniques (65.5\%) and aided them to differentiate between different devices and their specific techniques (64.3\%). Only $29.8 \%$ strongly agreed on the adequacy of the amount of inhaler devices learning content in the curriculum. However, this study did not seek further qualitative exploration into what areas might be needed to improve the perceived insufficiency. $85.7 \%$ of students ranked simulation as the preferred method of gaining knowledge and skills pertaining to the use of inhaler devices and ranked lectures as the least preferred.
Out of a maximum score of 40, a mean score of 34.15 (SD $=4.78$ ) denoted positive perception of inhaler skills gained after completing the curriculum. Almost all students reported being able to demonstrate inhalation techniques for MDI (98.8\%) and DPI (92.8\%). Students' perceptions of inhaler skills gained are summarised in Table II.

Students' performance in counselling on the use of the Turbuhaler device during OSCE is summarised in Table III. Out of a maximum score of 14 , the mean score obtained for the OSCE case was 9.4 (SD=2.7), which indicated good performance. Despite this, this study did not find any correlation between perceived inhaler skills gained with students' OSCE performance scores for counselling on Turbuhaler $(r=0.03, p=0.77)$. 
Table II: Students' perception on inhaler skills gained from the pharmacy curriculum $(\mathrm{N}=84)$

\begin{tabular}{|c|c|c|c|c|}
\hline \multirow[t]{2}{*}{ Survey items } & \multicolumn{4}{|c|}{ n (\%) } \\
\hline & Not well at all & Not very well & Quite well & Very well \\
\hline \multicolumn{5}{|c|}{ As a result of completing the BPharm curriculum, I can: } \\
\hline $\begin{array}{l}\text { Demonstrate inhalation techniques for } \\
\text { metered-dose inhaler devices }\end{array}$ & $0(0.0)$ & $1(1.2)$ & $42(50.0)$ & $41(48.8)$ \\
\hline $\begin{array}{l}\text { Demonstrate inhalation techniques for } \\
\text { dry-powder inhaler devices. }\end{array}$ & $1(1.2)$ & $5(6.0)$ & $50(59.5)$ & $28(33.3)$ \\
\hline $\begin{array}{l}\text { Recommend instructions for cleaning } \\
\text { metered-dose inhaler devices. }\end{array}$ & $0(0.0)$ & $1(1.2)$ & $39(46.4)$ & $44(52.4)$ \\
\hline $\begin{array}{l}\text { Recommend instructions for cleaning } \\
\text { dry-powder inhaler devices. }\end{array}$ & $1(1.2)$ & $8(9.5)$ & $38(45.2)$ & $37(44.0)$ \\
\hline $\begin{array}{l}\text { Guide checking of doses left within a } \\
\text { metered-dose inhaler device. }\end{array}$ & $0(0.0)$ & $5(6.0)$ & $46(54.8)$ & $33(39.3)$ \\
\hline $\begin{array}{l}\text { Guide checking of doses left within a } \\
\text { dry-powder inhaler device. }\end{array}$ & $1(1.2)$ & $6(7.1)$ & $45(53.6)$ & $32(38.1)$ \\
\hline $\begin{array}{l}\text { Advice storage conditions of various } \\
\text { inhaler devices. }\end{array}$ & $0(0.0)$ & $2(2.4)$ & $35(41.7)$ & $47(56.0)$ \\
\hline $\begin{array}{l}\text { Demonstrate inhalation techniques } \\
\text { when using a spacer device. }\end{array}$ & $0(0.0)$ & $1(1.2)$ & $40(47.6)$ & $43(51.2)$ \\
\hline $\begin{array}{l}\text { Recommend instructions for cleaning of } \\
\text { a spacer device. }\end{array}$ & $1(1.2)$ & $1(1.2)$ & $37(44.0)$ & 45 (53.6) \\
\hline $\begin{array}{l}\text { Counsel patients on lifestyle changes } \\
\text { needed when living with a chronic } \\
\text { respiratory condition. }\end{array}$ & $0(0.0)$ & $3(3.6)$ & $41(48.8)$ & $40(47.6)$ \\
\hline
\end{tabular}

Table III: Students' inhaler techniques during Objective Structured Clinical Examination ( $\mathrm{N}=84)$

\begin{tabular}{|c|c|c|c|}
\hline \multirow{2}{*}{\multicolumn{2}{|c|}{ Turbuhaler techniques }} & \multicolumn{2}{|c|}{$n(\%)$} \\
\hline & & Missed technique & Correct technique \\
\hline 1. & *Unscrew and remove cover. & $29(34.5)$ & $55(65.5)$ \\
\hline 2. & *Hold Turbuhalerin an upright position. & $28(33.3)$ & $56(66.7)$ \\
\hline 3. & $\begin{array}{l}{ }^{*} \text { Twist grip anti-clockwise to the right then back } \\
\text { again until a click sound is heard. }\end{array}$ & $3(3.6)$ & $81(96.4)$ \\
\hline 4. & $\begin{array}{l}\text { Turn head away from the inhaler and exhale to } \\
\text { residual volume. }\end{array}$ & $15(17.9)$ & $69(82.1)$ \\
\hline 5. & $\begin{array}{l}\text { Place Turbuhaler mouthpiece between lips, } \\
\text { ensuring a tight seal. }\end{array}$ & $3(3.6)$ & $81(96.4)$ \\
\hline 6. & *Inhale forcefully and deeply as possible. & $1(1.2)$ & $83(98.8)$ \\
\hline 7. & $\begin{array}{l}\text { Remove Turbuhaler from mouth and hold breath } \\
\text { for up to } 6-10 \text { seconds. }\end{array}$ & $6(7.1)$ & 78 (92.9) \\
\hline 8. & Exhale away from the Turbuhaler. & $17(20.2)$ & $67(79.8)$ \\
\hline 9. & $\begin{array}{l}\text { For another dose, repeat the steps after } 30-60 \\
\text { seconds. }\end{array}$ & $35(41.7)$ & $49(58.3)$ \\
\hline 10. & $\begin{array}{l}\text { Expect to taste sweetness as indicator of drug } \\
\text { delivery. }\end{array}$ & $80(95.2)$ & $4(4.8)$ \\
\hline 11. & Rinse mouth with water after using the Turbuhaler. & $38(45.2)$ & $46(54.8)$ \\
\hline 12. & Keep the Turbuhaler clean at all times. & $38(45.2)$ & $46(54.8)$ \\
\hline 13. & Replace the cover securely after each opening. & $54(64.3)$ & $30(35.7)$ \\
\hline 14. & $\begin{array}{l}\text { Store in a dry place at room temperature to avoid } \\
\text { moisture. }\end{array}$ & $38(45.2)$ & $46(54.8)$ \\
\hline
\end{tabular}

Steps 1 - 8 modified from Basheti and authors (Basheti et al., 2014)

*Essential steps (steps, if performed incorrectly, will minimize delivery of effective dose to the lungs) written in italics. 


\section{Discussion}

In Malaysia, Bachelor of Pharmacy graduates undergo one year of provisional training after graduation to qualify for full registration as a pharmacist. Provisionally registered pharmacists typically undergo validation of their medication devices counselling skills during this one-year training as part of the mandatory workplace-based assessment. Although counselling skills can be refined during on job training, the majority of knowledge and skills on medicinal devices were already obtained during their undergraduate studies.

In the present BPharm curriculum, students generally reported having had exposure of up to five hours on the inhaler devices teaching-learning activities. In this study, slightly more than half of the students have had a chance to teach inhaler techniques to real patients during their various experiential learning at primary care clinics or during pharmacy practice attachments or clinical clerkships at the hospitals. Students reported having practised their inhaler device technique within their most current semester showing high responsibility and accountability in retaining knowledge. Students preferred simulation and workshops as a method of gaining knowledge and skills on inhaler devices. Various studies reported numerous benefits of simulation-based approaches, including improvement in students' communications skills, increased knowledge retention and improved empathy (Kane-Gill \& Smithburger, 2011). Basheti and authors reported that students exposed to simulated patients felt a sense of the real-world in the academic setting and had demonstrated better inhaler counselling skills (Basheti, 2014). In light of this, counselling of simulated asthmatics patients can be incorporated into the asthma workshop to improve the BPharm curriculum.

Despite the fact that the use of DPI is easier than MDI, after going through the curriculum, slightly more students reported being able to perform MDI counselling than DPI. The ease of use of DPI is apparent with no need for hand-mouth coordination, which is required for effective use of pMDI (Rau \& Faarc, 2006). However, the use of DPI also comes with issues central to the inhaler design. DPIs require deep and forceful inhalation to mechanically move the dry powder against intrinsic device resistance and into the respiratory tract. Additionally, users of DPIs must take care not to exhale into the DPI mouthpiece, as doing so may result either in agglomeration of micronised dry powder or blowing out of the powder from the device (Fink \& Rubin, 2005; Rau \& Faarc, 2006).

With landmark changes to GINA in 2019, prescriptions of inhaled corticosteroids (ICS) are expected to increase with the advocacy of symptoms-driven ICS use (Global initiative for asthma: Asthma management and prevention, 2019). One of the inhaler devices containing a combination of budesonide and formoterol includes the DPI Turbuhaler. In addition to the Turbuhaler checklist proposed in a review by Basheti and authors (Basheti et al., 2014), the significance of this study is that the OSCE assessments incorporated additional counselling points such as explaining the sweet taste of lactose, need for gargling and advice on cleaning and storage for complete patient education. Topical adverse drug reactions related to ICS use are largely due to not gargling after ICS use (Kajiwara et al., 2014). Despite physical demonstration during OSCE, many students frequently missed orating steps one and two in the checklist (Table III), which have been reported as essential steps in ensuring effective dose delivery to the lungs. Holding the Turbuhaler upright is necessary to allow accurate metering of a single dose of powder from the reservoir by gravity into the dosing well, ready for inhalation (Basheti et al., 2014). Students also often missed informing on the sweetness of lactose and replacing the Turbuhaler cover after use. For a more complete education on inhaler technique, providers should also strive to increase patient's literacy on inhaler drug delivery, such as how will patients know it has worked, how it is expected to feel or taste, how much amount of medication is left and where to store the inhaler (Fink \& Rubin, 2005). Likewise, among important attributes of an inhaler considered by patients includes an indication of whether a dose has been taken correctly (Molimard \& Colthorpe, 2015). Despite high reported inhaler skills gained and good overall class performance in the counselling of Turbuhaler during OSCE, there was no statistically significant association identified between students' performance on Turbuhaler counselling skills using students' OSCE marks as indicators. OSCE has been previously reported as immensely stressful by examinees, and timeallocated at stations was limited (Awaisu, Mohamed, \& Al-Efan, 2007).

Inhaler device teaching-learning in the present BPharm curriculum is comparable with other pharmacy programme curriculum published in the literature. At the University of Sydney, Australia, a two-hour workshop was allocated at the end of the respiratory block during the second year of study for hands-on exposure with inhaler devices (Toumas-Shehata et al., 2018). In Amman, Jordan, final year students were given additional materials for reading after their respiratory therapeutics lecture along with a hands-on session with inhaler devices and counselling on a simulated asthma patient (Basheti, 2014). Schools of Pharmacy in the United States expose students to two to four hours of inhaler device techniques training as foundational skills in pharmacy practice labs in the first or second year of study, with competency in inhaler technique and lifestyle counselling gauged through 
OSCE in the same year or later years of study (Thurmon, Schwartz, \& Jervis, 2013; Ma et al., 2015; McMillan \& Barrickman, 2017). The US Accreditation Council for Pharmacy Education Standards 2016 states that all pharmacy programmes should incorporate measures in the curriculum to enable the graduate to impart skills in patient care as the expert in medication therapy.

With technological advancements, novel methods for inhaler education such as serious interactive games can be more easily created. Researchers from the National University of Singapore created a 3D virtual world simulation of a medical ward and avatars to educate care providers on inhaler counselling techniques for patients (Chee et al., 2019). Such methods can be especially useful during situations where social distancing measures limit face-to-face teaching and learning encounters. Although such methods can be used to reinforce existing knowledge and skills related to inhaler devices and improve retention of information, they cannot be substituted with the actual hands-on session of acquiring the psychomotor skills needed to use the device.

There are some limitations to the study. Cross-sectional data collection on students' perception and experience with inhaler teaching and learning in the curriculum was taken after the final semester had been completed, which predisposes to recall bias. This study only enrolled one batch of students, which limits the generalisability of the findings. For better generalisation of results, repeating the questionnaire and obtaining objective data on students' performance on dry-powder inhaler counselling could be undertaken for subsequent cohorts of students. Nevertheless, the study findings were useful to inform curriculum makers on the effectiveness of the current teaching-learning activities and students' competency performance. Finally, the inter-grader variability during OSCE was minimised by a standardised briefing on the assessment rubric and training of all assessors involved.

\section{Conclusions}

With greater development and focus on inhaled devices, strong inhaler skills should be inculcated during undergraduate pharmacy studies. The current teaching and learning strategies for inhaler devices allowed students to gain sufficient skills where they were able to demonstrate effective counselling of the Turbuhaler during their final progress testing. However, counselling points such as expected taste and advice on gargling should be highlighted. Additions to the curriculum can include the future use of the patient simulation scenario and increased exposure to real-life patient inhaler counselling during advanced experiential learning in primary care clinics or hospitals.

\section{Funding}

The authors received no financial support for the research, authorship, and/or publication of this article.

\section{Conflict of Interests}

The authors declare that there are no conflicts of interest.

\section{Acknowledment}

The authors would like to thank the Faculty of Pharmacy, University of Cyberjaya for their support in the conduct of this study.

\section{References}

Awaisu, A., Mohamed, M. H. N., \& Al-Efan, Q. A. M. (2007). Perception of pharmacy students in Malaysia on the use of objective structured clinical examinations to evaluate competence. American Journal of Pharmaceutical Education, 71(6), 118. https://doi.org/10.5688/aj7106118

Basheti, I. A. (2014). The effect of using simulation for training pharmacy students on correct device technique. American Journal of Pharmaceutical Education, 78(10), 1-10. https://doi.org/10.5688/ajpe7810177

Basheti, I. A., Bosnic-Anticevich, S. Z., Armour, C. L., \& Reddel, H. K. (2014). Checklists for powder inhaler technique: A review and recommendations. Respiratory Care, 59(7), 1140-1154. https://doi.org/10.4187/respcare.02342

Basheti, I. A., Qunaibi, E. A., Hamadi, S. A., \& Reddel, H. K. (2014). Inhaler technique training and healthcare professionals: Effective long-term solution for a current problem. Respiratory Care, 59(11), 1716-1725. https://doi.org/10.4187/respcare.02671

Chee, E. J. M., Prabhakaran, L., Neo, L. P., Carpio, G. A. C., Tan, A. J. Q., Lee, C. C. S., \& Liaw, S. Y. (2019). Play and learn with patients-designing and evaluating a serious game to enhance nurses' inhaler teaching techniques: A randomized controlled trial. Games for Health Journal, 8(3), 187-194. https://doi.org/10.1089/g4h.2018.0073

Chrystyn, H., Van Der Palen, J., Sharma, R., Barnes, N., Delafont, B., Mahajan, A., \& Thomas, M. (2017). Device errors in asthma and COPD: Systematic literature review and metaanalysis. Npj Primary Care Respiratory Medicine, 27(1), 1-9. https://doi.org/10.1038/s41533-017-0016-z

Croft, H., Gilligan, C., Rasiah, R., Levett-Jones, T., \& Schneider, J. (2019). Current Trends and Opportunities for Competency Assessment in Pharmacy Education-A Literature Review. Pharmacy, 7(2), 67. https://doi.org/10.3390/pharmacy7020067

Fink, J. B., \& Rubin, B. K. (2005). Problems with inhaler use: A call for improved clinician and patient education. Respiratory Care, 50(10), 1360-1374 
Global Initiative for Asthma. Global strategy for asthma management and prevention, 2019. https://ginasthma.org/wpcontent/uploads/2020/04/GINA-2020-full-report_-final_wms.pdf

Holman, H., \& Lorig, K. (2004). Patient self-management: A key to effectiveness and efficiency in care of chronic disease. Public Health Reports, 119(3), 239-243. https://doi.org/10.1016/j.phr.2004.04.002

Jeffries, P. R., \& Rizzolo, M. A. (2006). Designing and implementing models for the innovative use of simulation to teach nursing care of ill adults and children : a national, multisite, multi-method study. National League for Nursing, 1-17

Kajiwara, A., Kita, A., Saruwatari, J., Morita, K., Oniki, K., Yamamura, M., ... Nakagawa, K. (2014). Absence of gargling affects topical adverse symptoms caused by inhaled corticosteroids in females. Journal of Asthma, 51(2), 221224. https://doi.org/10.3109/02770903.2013.857683

Kane-Gill, S. L., \& Smithburger, P. L. (2011). Transitioning knowledge gained from simulation to pharmacy practice. American Journal of Pharmaceutical Education, 75(10), 1-9. https://doi.org/10.5688/ajpe7510210

Lavorini, F., Magnan, A., Christophe Dubus, J., Voshaar, T., Corbetta, L., Broeders, M., ... Crompton, G. K. (2008). Effect of incorrect use of dry powder inhalers on management of patients with asthma and COPD. Respiratory Medicine, 102(4), 593-604. https://doi.org/10.1016/j.rmed.2007.11.003

Levy, M. L., Hardwell, A., McKnight, E., \& Holmes, J. (2013). Asthma patients' inability to use a pressurised metered-dose inhaler (pMDI) correctly correlates with poor asthma control as defined by the Global Initiative for Asthma (GINA) strategy: A retrospective analysis. Primary Care Respiratory Journal, 22(4), 406-411. https://doi.org/10.4104/pcrj.2013.00084

Ma, C. S., Nett, B., Kishaba, G., \& Gomez, L. (2015). Impact of utilizing pharmacy students as workforce for Hawai'i Asthma Friendly Pharmacy Project. Hawai'i Journal of Medicine \& Public Health: A Journal of Asia Pacific Medicine \& Public Health, 74(2), 57-62

McMillan, A., \& Barrickman, A. (2017). Implementation of a skills practical to first-year pharmacy students. Currents in Pharmacy Teaching and Learning, 9(6), 1111-1116. https://doi.org/10.1016/j.cptl.2017.07.024

Melani, A. S., Bonavia, M., Cilenti, V., Cinti, C., Lodi, M., Martucci, P., ... Neri, M. (2011). Inhaler mishandling remains common in real life and is associated with reduced disease control. Respiratory Medicine, 105(6), 930-938. https://doi.org/10.1016/j.rmed.2011.01.005

Molimard, M., \& Colthorpe, P. (2015). Inhaler devices for chronic obstructive pulmonary disease: Insights from patients and healthcare practitioners. Journal of Aerosol Medicine and Pulmonary Drug Delivery, 28(3), 219-228. https://doi.org/10.1089/jamp.2014.1142

Plaza, V., Giner, J., Rodrigo, G. J., Dolovich, M. B., \& Sanchis, J. (2018). Errors in the Use of Inhalers by Health Care Professionals: A Systematic Review. Journal of Allergy and Clinical Immunology: In Practice, 6(3), 987-995. https://doi.org/10.1016/j.jaip.2017.12.032

Price, D., Bosnic-Anticevich, S., Briggs, A., Chrystyn, H., Rand, C., Scheuch, G., \& Bousquet, J. (2013). Inhaler competence in asthma: Common errors, barriers to use and recommended solutions. Respiratory Medicine, 107(1), 37-46. https://doi.org/10.1016/j.rmed.2012.09.017

Rau, J. L. (2005). The inhalation of drugs: Advantages and problems. Respiratory Care, 50(3), 367-382

Rau, J. L., \& Faarc, R. R. T. (2006). Practical problems with aerosol therapy in COPD. Respiratory Care. 51(2), 158- 172

Restrepo, R. D., Alvarez, M. T., Wittnebel, L. D., Sorenson, H., Wettstein, R., Vines, D. L., ... Wilkins, R. L. (2008). Medication adherence issues in patients treated for COPD. International Journal of COPD, 3(3), 371384. https://doi.org/10.2147/copd.s3036

Shirwaikar, A. (2015). Objective structured clinical examination (OSCE) in pharmacy education- A trend. Pharmacy Practice, 13(4), 1-5. https://doi.org/10.18549/PharmPract.2015.04.627

Slain, D., Abate, M., Hodges, B. M., Stamatakis, M. K., \& Wolak, S. (2004). An interactive response system to promote active learning in the doctor of pharmacy curriculum. American Journal of Pharmaceutical Education, 68(5), 1-9. https://doi.org/10.5688/aj6805117

Taylor-Powell, E., \& Renner, M. (2009). Collecting evaluation data: End-of-session questionnaires. University of Wisconsin-Extension, Cooperative Extension, Madison. 2009. https://cdn.shopify.com/s/files/1/0145/8808/4272/files/G3 658-11.pdf. Accessed April 15, 2019

Thurmon, T. B., Schwartz, L. L., \& Jervis, K. P. (2013). Asthma education in the student laboratory. Journal of Pharmacy Practice, 26(1), 29-31. https://doi.org/10.1177/0897190012466045

Toumas-Shehata, M., Henricks, M., Ovchinikova, L., Smith, L., \& Bosnic-Anticevich, S. (2018). Teaching Pharmacy Undergraduate Students Inhaler Device Technique and Exploring Factors Affecting Maintenance of Technique. Canadian Respiratory Journal, 2018, 13-15. https://doi.org/10.1155/2018/1597217

Van Boven, J. F. M., Chavannes, N. H., Van Der Molen, T., Rutten-Van Mölken, M. P. M. H., Postma, M. J., \& Vegter, S. (2014). Clinical and economic impact of non-adherence in COPD: A systematic review. Respiratory Medicine, 108(1), 103-113. https://doi.org/10.1016/j.rmed.2013.08.044

Volerman, A., Carpenter, D., \& Press, V. G. (2020). What can be done to impact respiratory inhaler misuse: exploring the problem, reasons, and solutions. Expert Review of Respiratory Medicine, null-null. https://doi.org/10.1080/17476348.2020.1754800

Vyas, D., Wombwell, E., Russell, E., \& Caligiuri, F. (2010). High-fidelity patient simulation series to supplement introductory pharmacy practice experiences. American Journal of Pharmaceutical Education, 74(9), 1-8. https://doi.org/10.5688/aj7409169 